\title{
Simultaneous Determination of Mebeverine Hydrochloride and Sulpiride Using the First Derivatives of Ratio Spectra and Chemometric Methods
}

\author{
S. I. M. ZAYED \\ Faculty of Industrial Education, Beni Suef, Egypt
}

\begin{abstract}
Two methods are described for the simultaneous determination of mebeverine hydrochloride (MB) and sulpiride (SU) in their combinations. The first method depends on the first derivative of the ratio spectra by measurement of the amplitudes at 263.7 and $234.9 \mathrm{~nm}$ for MB and SU, respectively. The linear ranges and detection limits are $4.0-40.0$ and $0.72 \mu \mathrm{g} / \mathrm{ml}$ for $\mathrm{MB}$ and $1.0-10.0$ and $0.34 \mu \mathrm{g} / \mathrm{ml}$ for SU. In the second case, a chemometric (classical least squares) method was developed. The concentration data matrices were obtained by using different concentrations of pure drugs in $0.1 \mathrm{M} \mathrm{HCl}$. The absorbance data matrix corresponding to each concentration data matrix was obtained by the measurements of absorbances in the range $200-300 \mathrm{~nm}$ in their zero order spectra; then calibration was obtained by using the absorbance data matrix and the concentration data matrix for the prediction of the unknown concentrations of $\mathrm{MB}$ and SU in their mixture. The numerical values were calculated by using Matlab R12 version 6.0 and Origin 5.0 software. The procedures do not require any separation steps. These two methods were successfully applied for assaying the pharmaceutical formulation, of Colona tablets.
\end{abstract}

(Received October 5, 2004; Accepted February 16, 2005)

\section{Introduction}

Mebeverine hydrochloride (MB), 4-[ethyl(4-methoxy- $\alpha$ methylphenethyl)amino]butyl veratrate hydrochloride [2753-459], is a potent direct antispasmodic acting mainly on the smooth muscles of the gastrointestinal tract; it is particularly effective against colonic spasms. ${ }^{1}$ Sulpiride (SU), $N$-(1-ethylpyrrolidin2-ylmethyl)-2-methoxy-5-sulfamoyl benzamide [15676-16-1], is a substituted benzamide antipsychotic which is reported to be a selective antagonist of central dopamine $\left(D_{2}, D_{3}\right.$ and $\left.D_{4}\right)$ receptors. It is also claimed to have mood-elevating properties. ${ }^{1}$ The binary mixture of the two drugs is used in the treatment of gastointestinal and colic spasms, specially in the presence of psychasomatic manifestations of nervous tension, mental stress or anxiety. Several analytical methods have been used for the determination of $\mathrm{MB}$, including high performance liquid chromatography (HPLC), ${ }^{2-4}$ thin layer chromatography (TLC),, 5 spectrophotometric methods ${ }^{7-10}$ and derivative UV spectrophotometric method in the presence of their alkaline induced degradation products. ${ }^{11}$ A literature survey also reveals several methods for assaying SU, involving HPLC, , 12-15 TLC, ${ }^{16,17}$ fluorometric, ${ }^{18}$ spectrophotometric, ${ }^{19,20}$ flow injection chemiluminometric, ${ }^{21}$ capillary electrophoresis, ${ }^{22}$ oscillopolarographic, ${ }^{23}$ and adsorptive stripping voltammetric ${ }^{24}$ methods. El-Walily et $a l .^{25}$ first used derivative UV spectrophotometry, TLC-densitometry and HPLC for the simultaneous determination of both of these two compounds in pharmaceutical tablets. In this study, ratio spectra first derivative spectrophotometry and classical least squares method are proposed for simultaneous determination of MB and SU in their mixtures and their pharmaceutical preparation, Colona tablets. The proposed ratio spectra first derivative method was found to be more sensitive than the published UV first derivative method ${ }^{25}$ (Beer's law linear range was 4.0-40.0 and $1.0-10.0 \mu \mathrm{g} / \mathrm{ml}$ for $\mathrm{MB}$ and $\mathrm{SU}$, respectively while the linear range was $10.0-30.0$ and $2.0-8.0 \mu \mathrm{g} / \mathrm{ml}$ in the first derivative published method). The proposed chemometric method was more rapid, simple than the published methods. ${ }^{25}$ Also, the proposed methods can be used as alternative methods to those reported for the simultaneous determination of MB and SU.

\section{Experimental}

Apparatus

A Shimadzu 1601 double beam UV-Vis spectrophotometer with a fixed slit width $(2 \mathrm{~nm})$ connected to an IBM compatible computer and a HP 600 inkjet printer was used. The bundled software was UV PC personal spectroscopy version 3.91 (Shimadzu).

\section{Materials}

$\mathrm{MB}, \mathrm{SU}$ and Colona tablets containing $100 \mathrm{mg} \mathrm{MB}$ and $25 \mathrm{mg}$ SU per tablet, were kindly supplied by Rameda (6 October City, Egypt). Analytical grade methanol and hydrochloric acid were used throughout these experiments.

\section{Standard solutions}

Stock solutions of MB and of SU were prepared separately by dissolving $100 \mathrm{mg}$ and $10 \mathrm{mg}$ of each drug, respectively, in 100 $\mathrm{ml}$ methanol. The standard solutions were prepared by dilution of the stock solutions with $0.1 \mathrm{M} \mathrm{HCl}$ to reach a concentration range of $4-20$ and $1-10 \mu \mathrm{g} / \mathrm{ml}$ for $\mathrm{MB}$ and $\mathrm{SU}$, respectively. 


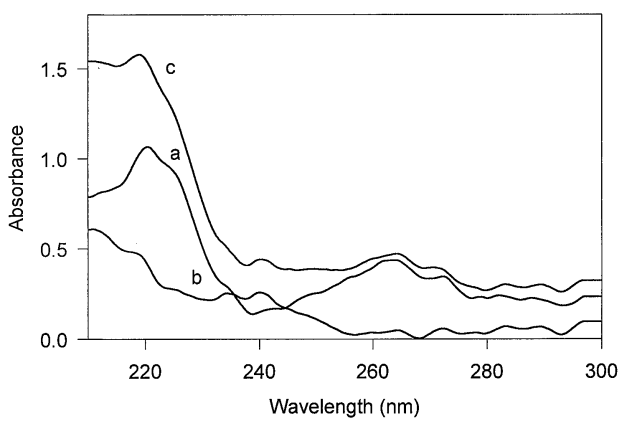

Fig. 1 Zero order spectra of (a) $16.0 \mu \mathrm{g} / \mathrm{ml} \mathrm{MB}$, (b) $4.0 \mu \mathrm{g} / \mathrm{ml} \mathrm{SU}$ in $0.1 \mathrm{M} \mathrm{HCl}$ and (c) their mixture.

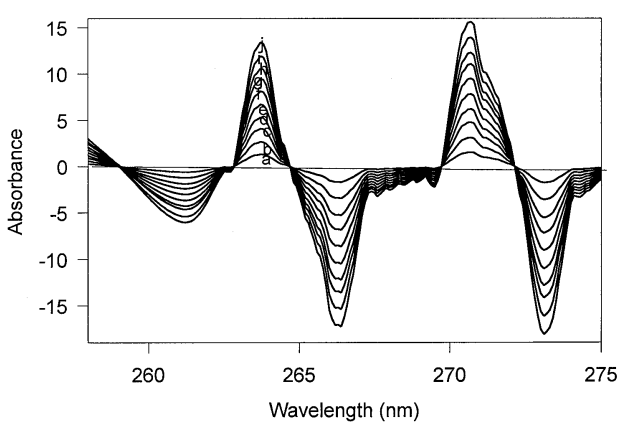

Fig. 2 First derivative of the ratio method of a, 4; b, 8; c, 12; d, 16; e, 20; f, 24; g, 28; h, 32; i, 36; j, $40 \mu \mathrm{g} / \mathrm{ml}$ solution of MB in $0.1 \mathrm{M}$ $\mathrm{HCl}$ when $6 \mu \mathrm{g} / \mathrm{ml}$ solution of SU in $0.1 \mathrm{M} \mathrm{HCl}$ used as divisor $(\Delta \lambda=$ $4 \mathrm{~nm})$.

\section{Sample preparation}

Twenty tablets were accurately weighed and powdered in a mortar. An amount of the tablet mass equivalent to one tablet was dissolved in about $60 \mathrm{ml}$ methanol and filtered in a $100 \mathrm{ml}$ measuring flask. The residue was washed three times with 10 $\mathrm{ml}$ methanol; then the volume was completed to the mark with the same solvent. This solution was diluted five times with 0.1 $\mathrm{M} \mathrm{HCl}$.

\section{Procedure}

For the first derivative of the ratio spectra method ${ }^{1} D D$. For $\mathrm{MB}$, the absorption spectra of the solutions prepared at different concentrations $(4-40 \mu \mathrm{g} / \mathrm{ml})$ in its binary mixture with SU were recorded against $0.1 \mathrm{M} \mathrm{HCl}$ and divided by the spectrum of the standard solution of $\mathrm{SU}(6 \mu \mathrm{g} / \mathrm{ml}$ in $0.1 \mathrm{M} \mathrm{HCl})$. The ratio spectra were thus obtained and smoothed; the first derivative of the ratio spectra were then calculated. The amount of $\mathrm{MB}$ can be determined by measuring the first derivative signal at $263.7 \mathrm{~nm}$. A similar procedure was followed for the different concentrations of SU $(1-10 \mu \mathrm{g} / \mathrm{ml})$ when $\mathrm{MB}$ was constant $(20 \mu \mathrm{g} / \mathrm{ml}$ in $0.1 \mathrm{M} \mathrm{HCl})$. In the same way as described above, the content of SU was determined by measuring the first derivative signal at $234.9 \mathrm{~nm}$.

Detection limits. In accordance with the formula given by Miller, ${ }^{26}$ the detection limit is $3 s / k$, where $s$ is the standard deviation of replicate determination values under the same conditions as for the sample analysis in the absence of the analyte and $k$ is the slope of the calibration graph.

For classical least squares method (CLS). In the CLS method, the concentration data matrices were prepared by using different concentrations of pure drugs in $0.1 \mathrm{M} \mathrm{HCl}$. The absorbance

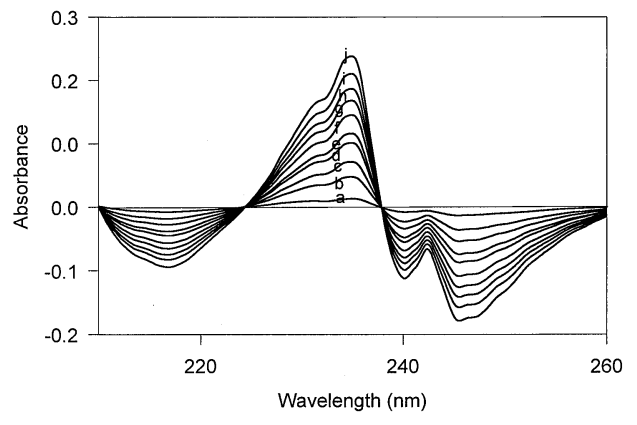

Fig. 3 First derivative of the ratio method of a, 1; b, 2; c, 3; d, 4; e, $5 ; \mathrm{f}, 6 ; \mathrm{g}, 7 ; \mathrm{h}, 8 ; \mathrm{i}, 9 ; \mathrm{j}, 10 \mu \mathrm{g} / \mathrm{ml}$ solution of $\mathrm{SU}$ in $0.1 \mathrm{M} \mathrm{HCl}$ when $20 \mu \mathrm{g} / \mathrm{ml}$ solution of $\mathrm{MB}$ in $0.1 \mathrm{M} \mathrm{HCl}$ used as divisor $(\Delta \lambda=4 \mathrm{~nm})$.

data matrix corresponding to the concentration data matrix was obtained by the measurements of absorbances in the range 200 $300 \mathrm{~nm}$ in their zero order spectra; then calibration was obtained by using the absorbance data matrix and concentration data matrix for the prediction of the unknown concentrations of $\mathrm{MB}$ and $\mathrm{SU}$ in synthetic mixtures and commercial tablets. The numerical values were calculated by using Matlab R12 version 6.0 and Origin 5.0 software. Calibration is based on a set of $n$ samples of known concentrations for which the spectra are measured. By means of the calibration sample set, estimation of absorptivities is possible by solving the matrix $\boldsymbol{K}$ according to the general least squares solution:

$$
\boldsymbol{K}=\left(\boldsymbol{C}^{\mathbf{T}} \boldsymbol{C}\right)^{-1} \boldsymbol{C}^{\mathbf{T}} \boldsymbol{A}
$$

where $\boldsymbol{C}$ is the calibration matrix; $\boldsymbol{A}$ is the absorbance matrix; $\boldsymbol{C}^{\mathbf{T}}$ is transpose of the matrix $\boldsymbol{C}$. The analysis is then based on the spectrum $\boldsymbol{a}_{0}$ of the unknown sample by using the equation:

$$
c_{0}=a_{0} K^{\mathrm{T}}\left(K K^{\mathrm{T}}\right)^{-1}
$$

where $\boldsymbol{c}_{\boldsymbol{0}}$ is the vector of predicted concentrations and $\boldsymbol{K}^{\mathbf{T}}$ is transpose of the matrix $\boldsymbol{K}$ ( $\boldsymbol{K}$ is the matrix of absorptivities).

\section{Results and Discussion}

The UV spectra of MB $(16 \mu \mathrm{g} / \mathrm{ml}), \mathrm{SU}(4 \mu \mathrm{g} / \mathrm{ml})$ in $0.1 \mathrm{M} \mathrm{HCl}$ and their mixture are reproduced in Fig. 1. It is clear that the spectra of the two drugs display considerable overlap; hence, the direct UV absorption measurement for assaying the binary mixture seems to be difficult.

\section{${ }^{I}$ DD method}

For determination of MB, the UV spectra of MB standards of increasing concentrations in $0.1 \mathrm{M} \mathrm{HCl}$ in its binary mixture with SU were divided by the spectrum of $6 \mu \mathrm{g} / \mathrm{ml} \mathrm{SU}$ solution in $0.1 \mathrm{M} \mathrm{HCl}$; the spectra obtained were smoothed and their first derivatives were calculated (Fig. 2).

As seen in the figure, there exist three maxima (255.9, 263.7 and $270.7 \mathrm{~nm}$ ) and three minima (261.2, 266.4 and $273.1 \mathrm{~nm})$. We found that measured signals at these wavelengths are proportional to the concentrations of the drug. In the synthetic mixtures, the mean recovery and the standard deviation were found to be $105.62 \pm 1.27,100.80 \pm 1.25,102.15 \pm 1.45,107.71$ $\pm 1.47,104.33 \pm 1.47$ and $103.98 \pm 1.80$ for peaks at 255.9 $263.7,270.7,261.2,266.4$ and $273.1 \mathrm{~nm}$, respectively. The $263.7 \mathrm{~nm}$ peak was selected for the determination of the drug in 
Table 1 Statistical analysis of calibration graphs in the determination of MB and SU using ${ }^{1} \mathrm{DD}$ method

\begin{tabular}{lcc}
\hline \multicolumn{1}{c}{ Parameter } & MB & SU \\
\hline$\lambda(\mathrm{nm})$ & 263.7 & 234.9 \\
Linearity $(\mu \mathrm{g} / \mathrm{ml})$ & $4-40$ & $1-10$ \\
Detection limits $(\mu \mathrm{g} / \mathrm{ml})$ & 0.72 & 0.34 \\
Regression equation $(Y)^{\mathrm{a}}$ & & \\
Slope $(b)$ & $33.34 \times 10^{-2}$ & $24.79 \times 10^{-3}$ \\
SD of slope $\left(S_{\mathrm{b}}\right)$ & $2.20 \times 10^{-3}$ & $3.36 \times 10^{-4}$ \\
Intercept $(a)$ & $20.97 \times 10^{-3}$ & $-9.70 \times 10^{-3}$ \\
SD of intercept $\left(S_{\mathrm{a}}\right)$ & $54.53 \times 10^{-3}$ & $2.67 \times 10^{-3}$ \\
Correlation coefficient $(r)$ & 0.9998 & 0.9995 \\
\hline
\end{tabular}

a. $Y=a+b C$ where $C$ is the concentration in $\mu \mathrm{g} / \mathrm{ml}$ and $Y$ is the amplitude at the specified wavelength.

the synthetic mixtures and commercial Colona tablets due to its low standard deviation value and suitable mean recovery; similarly, for determination of SU, UV spectra of SU standards of increasing concentrations in $0.1 \mathrm{M} \mathrm{HCl}$ in its binary mixture with $\mathrm{MB}$ were divided by the spectrum of $20 \mu \mathrm{g} / \mathrm{ml} \mathrm{MB}$. The ratio spectra obtained were smoothed and their first derivatives were calculated (Fig. 3). In these spectra, one maxium 234.9 $\mathrm{nm}$ and three minima 240.2, 245.5 and $216.9 \mathrm{~nm}$ were found. The measured signals at these wavelengths are proportional to the concentrations of the drug. In the synthetic mixtures, the mean recovery and standard deviation were found to be $99.22 \pm$ $1.56,94.58 \pm 1.95,100.91 \pm 2.32$ and $102.25 \pm 2.77$ for peaks at $234.9,240,2,245.5$ and 216.9 , respectively. We selected the $234.9 \mathrm{~nm}$ maxima for determination of SU in the synthetic mixtures and commercial tablets due to its lower standard deviation value and suitable mean recovery.

In order to determine the divisor concentration, we assayed different concentrations over the range $4-40 \mu \mathrm{g} / \mathrm{ml}$ for MB and $1-10 \mu \mathrm{g} / \mathrm{ml}$ for SU. Then, $6 \mu \mathrm{g} / \mathrm{ml} \mathrm{SU}$ and $20 \mu \mathrm{g} / \mathrm{ml} \mathrm{MB}$ were chosen as optimum values; the $\Delta \lambda$ found as optimum for the first derivative of their ratio spectra was $4 \mathrm{~nm}$. Calibration graphs were established for standards containing $4-40 \mu \mathrm{g} / \mathrm{ml}$ $\mathrm{MB}$ at $263.7 \mathrm{~nm}$ and for standards containing $1-10 \mu \mathrm{g} / \mathrm{ml} \mathrm{SU}$ at $234.9 \mathrm{~nm}$. A critical evalution of the proposed method was performed by the statistical analysis of the experimental data; regression curves were obtained by the least squares method. The obtained slopes, intercepts and correlation coefficients $r$ are summarized in Table 1.

The correlation coefficients were 0.9998 and 0.9995 for MB and SU, respectively, indicating good linearity; standard deviations of the methods were found to be satisfactory. The detection limits of the proposed methods were calculated ${ }^{26}$ the calculated detection limits are 0.72 and $0.34 \mu \mathrm{g} / \mathrm{ml}$ in the determinations of $\mathrm{MB}$ and $\mathrm{SU}$, respectively. In order to demonstrate the validity and applicability of the proposed method, we performed recovery studies by analyzing synthetic mixtures of $\mathrm{MB}$ and SU which reproduced different composition ratios; the results are summarized in Table 2.

\section{CLS method}

In this method, the concentration data matrices were prepared by using different concentrations of pure drugs in $0.1 \mathrm{M} \mathrm{HCl}$. The absorbance data matrix corresponding to the concentration data matrix was obtained by the measurements of absorbances in the range 200-300 $\mathrm{nm}$ in their zero order spectra; then calibration was obtained by using the absorbance data matrix and concentration data matrix for the prediction of the unknown concentrations of $\mathrm{MB}$ and $\mathrm{SU}$ in synthetic mixtures and
Table 2 Recovery data obtained for synthetic different mixtures by using ${ }^{1} \mathrm{DD}$ method

\begin{tabular}{|c|c|c|c|c|c|c|}
\hline \multirow[b]{2}{*}{ Sample } & \multicolumn{3}{|c|}{ MB } & \multicolumn{3}{|c|}{ SU } \\
\hline & $\begin{array}{l}\text { Added/ } \\
\mu \mathrm{g} \mathrm{ml}^{-1}\end{array}$ & $\begin{array}{l}\text { Found/ } \\
\mu \mathrm{g} \mathrm{ml}^{-1}\end{array}$ & $\begin{array}{c}\text { Recovery, } \\
\%\end{array}$ & $\begin{array}{l}\text { Added/ } \\
\mu \mathrm{g} \mathrm{ml}^{-1}\end{array}$ & $\begin{array}{l}\text { Found/ } \\
\mu \mathrm{g} \mathrm{ml}^{-1}\end{array}$ & $\begin{array}{c}\text { Recovery, } \\
\%\end{array}$ \\
\hline 1 & 20.00 & 19.90 & 99.50 & 4.00 & 3.85 & 96.25 \\
\hline 2 & 20.00 & 19.86 & 99.30 & 5.00 & 4.94 & 98.80 \\
\hline 3 & 20.00 & 20.51 & 102.55 & 7.00 & 6.94 & 99.14 \\
\hline 4 & 20.00 & 20.49 & 102.45 & 8.00 & 7.90 & 98.75 \\
\hline 5 & 12.00 & 12.00 & 100.00 & 5.00 & 5.06 & 101.20 \\
\hline 6 & 14.00 & 14.20 & 101.43 & 5.00 & 5.04 & 100.80 \\
\hline 7 & 16.00 & 16.07 & 100.44 & 5.00 & 5.01 & 100.20 \\
\hline 8 & 18.00 & 18.13 & 100.72 & 5.00 & 4.93 & 98.60 \\
\hline Mean & & & 100.80 & & & 99.22 \\
\hline SD & & & 1.248 & & & 1.558 \\
\hline RSD & & & 1.238 & & & 1.570 \\
\hline SEP & & & 0.272 & & & 0.079 \\
\hline SEC & & & 0.344 & & & 0.100 \\
\hline
\end{tabular}

SEP: Standard error of prediction.

SEC: Standard error of calibration.

Table 3 Recovery data obtained for determination of MB and SU in synthetic different mixtures by using CLS method

\begin{tabular}{ccccccccc}
\hline & \multicolumn{3}{c}{ MB } & & \multicolumn{3}{c}{ SU } \\
\cline { 2 - 4 } \cline { 6 - 7 } Sample & Added/ & Found/ & Recovery, & Added/ & Found/ & Recovery, \\
& $\mu \mathrm{g} \mathrm{ml}^{-1}$ & $\mu \mathrm{g} \mathrm{ml}^{-1}$ & $\%$ & & $\mu \mathrm{g} \mathrm{ml}^{-1}$ & $\mu \mathrm{g} \mathrm{ml}{ }^{-1}$ & $\%$ \\
\hline & 20.00 & 20.24 & 101.20 & & 4.00 & 3.90 & 97.50 \\
2 & 20.00 & 19.98 & 99.90 & & 5.00 & 4.97 & 99.40 \\
3 & 20.00 & 20.29 & 101.45 & & 7.00 & 7.06 & 100.86 \\
4 & 20.00 & 20.10 & 100.50 & & 8.00 & 8.08 & 101.00 \\
5 & 12.00 & 12.18 & 101.50 & & 5.00 & 5.18 & 103.60 \\
6 & 14.00 & 14.39 & 102.79 & & 5.00 & 5.15 & 103.00 \\
7 & 16.00 & 16.25 & 101.56 & & 5.00 & 5.13 & 102.60 \\
8 & 18.00 & 18.28 & 101.56 & & 5.00 & 4.96 & 99.20 \\
Mean & & & 101.31 & & & 100.90 \\
SD & & & 0.847 & & & 2.115 \\
RSD & & & 0.836 & & & 2.096 \\
SEP & & & 0.244 & & & 0.109 \\
SEC & & & 0.309 & & & 0.137 \\
\hline
\end{tabular}

SEP: Standard error of prediction.

SEC: Standard error of calibration.

commercial tablets. In order to demonstrate the validity and applicability of the proposed method, we performed recovery studies by analyzing synthetic mixtures of MB and SU which represent different composition ratios; the results are summarized in Table 3. The predicted concentrations of the components in each sample were compared with the known concentrations in this sample and the standard error of prediction (SEP) was calculated using the following equation:

$$
\mathrm{SEP}=\sqrt{\frac{\sum_{\mathrm{i}=1}^{\mathrm{N}}\left(C_{\mathrm{i}=1}^{\text {Added }}-C_{\mathrm{i}}^{\text {Found }}\right)^{2}}{n}}
$$

Here $C_{\mathrm{i}}$ Added is the added concentration of the drug, $C_{\mathrm{i}}{ }^{\text {Found }}$ is the predicted concentration of the drug and $n$ is the total number of synthetic mixtures.

The standard error of prediction (SEP) values were acceptable 
Table 4 Recovery results for MB and SU in commercial Colona tablets using ${ }^{1} \mathrm{DD}$ and CLS methods

\begin{tabular}{|c|c|c|c|c|c|c|c|c|c|c|c|c|c|}
\hline \multirow{2}{*}{\multicolumn{2}{|c|}{ 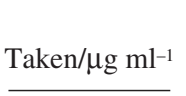 }} & \multicolumn{6}{|c|}{${ }^{1} \mathrm{DD}$} & \multicolumn{6}{|c|}{ CLS } \\
\hline & & \multicolumn{2}{|c|}{ Found/ $\mu \mathrm{g} \mathrm{ml}^{-1}$} & \multicolumn{2}{|c|}{ Recovery, \% } & \multicolumn{2}{|c|}{ RSD } & \multicolumn{2}{|c|}{ Found/ $\mu \mathrm{g} \mathrm{ml} \mathrm{m}^{-1}$} & \multicolumn{2}{|c|}{ Recovery, \% } & \multicolumn{2}{|c|}{ RSD } \\
\hline ІУБ & SU & MB & SU & MB & SU & MB & SU & $\mathrm{MB}$ & SU & MB & SU & MB & SU \\
\hline 16.00 & 4.00 & 15.76 & 4.03 & 98.50 & 100.75 & 0.640 & 1.013 & 15.72 & 4.03 & 98.25 & 100.75 & 1.314 & 1.472 \\
\hline 20.00 & 5.00 & 19.88 & 5.05 & 99.40 & 101.00 & 0.342 & 0.511 & 19.76 & 5.02 & 98.80 & 100.40 & 0.385 & 0.327 \\
\hline 24.00 & 6.00 & 23.94 & 6.06 & 99.75 & 101.00 & 1.647 & 1.286 & 23.88 & 6.12 & 99.50 & 102.00 & 0.498 & 0.254 \\
\hline 28.00 & 7.00 & 28.39 & 7.17 & 101.39 & 102.43 & 0.639 & 1.003 & 27.90 & 7.18 & 99.64 & 102.57 & 0.319 & 0.485 \\
\hline
\end{tabular}

RSD: Relative standard deviation (four determinations).

Table 5 Statistical comparison between results of commercial Colona tablets applying ${ }^{1} \mathrm{DD}$, CLS and reference method

\begin{tabular}{|c|c|c|c|c|c|c|}
\hline \multirow{2}{*}{ Parameter } & \multicolumn{2}{|c|}{${ }^{1} \mathrm{DD}$} & \multicolumn{2}{|c|}{ CLS } & \multicolumn{2}{|c|}{ Reference method ${ }^{25}$} \\
\hline & MB & SU & MB & SU & $\mathrm{MB}$ & SU \\
\hline Mean recovery, $\%$ & 99.76 & 101.30 & 99.05 & 101.43 & 98.88 & 100.61 \\
\hline $\mathrm{SD}$ & 0.815 & 0.966 & 0.621 & 0.642 & 0.413 & 0.437 \\
\hline RSD & 0.817 & 0.954 & 0.627 & 0.633 & 0.418 & 0.434 \\
\hline$F$-ratio $(9.28)^{\mathrm{a}}$ & 3.894 & 4.886 & 2.261 & 2.158 & & \\
\hline$t$-test $(2.447)^{\mathrm{b}}$ & 1.926 & 1.301 & 0.456 & 2.112 & & \\
\hline
\end{tabular}

Average of four determinations for the ${ }^{1}$ DD and CLS methods. SD: Standard deviation. RSD: Relative standard deviation. a. Tabulated

$F$-value at $95 \%$ confidence level. b. Tabulated $t$-value at $95 \%$ confidence level and six degrees of freedom.

(0.272 and 0.079) for MB and SU in the first derivative of the ratio spectra method; the values were 0.244 and 0.109 in the classical least squares method (Tables 2 and 3). Mean recovery and RSD values for $\mathrm{MB}$ and SU were found to be 100.80 , $1.238,99.22$ and 1.570 , respectively in case of ${ }^{1} \mathrm{DD}$ method (Table 2), and 101.31, 0.836, 100.90, 2.096 in case of CLS method (Table 3). Also, the standard error of calibration (SEC) was calculated using the relation:

$$
\mathrm{SEC}=\sqrt{\frac{\sum_{\mathrm{i}=1}^{\mathrm{N}}\left(C_{\mathrm{i}=1}^{\text {Added }}-C_{\mathrm{i}}^{\text {Found }}\right)^{2}}{n-p-1}}
$$

where $C_{\mathrm{i}}^{\text {Added }}$ is the added concentration of the drug, $C_{\mathrm{i}}^{\text {Found }}$ is the predicted concentration of the drug, $n$ is the total number of synthetic mixtures and $p$ is the number of components in the mixtures. The standard error of calibration (SEC) values were also found acceptable: 0.344 and 0.100 for $\mathrm{MB}$ and SU in case of the ${ }^{1}$ DD method (Table 2), 0.309 and 0.137 in case of CLS method (Table 3).

\section{Application}

The two proposed methods were applied to the determination of MB and SU in Colona tablets (100 mg MB and $25 \mathrm{mg} \mathrm{SU}$ ). Satisfactory results were obtained for the recovery of both drugs (Table 4) and were in good agreement with label claims. Results indicate that there is no interference from the excipients used in the formulation of the tablets. As the dosage form of MB and SU is not pharmacopoeial yet, the results obtained by using the two methods were compared with published results obtained using UV first derivative reference method. ${ }^{25}$

Student $t$ - and $F$-tests (at 95\% confidence level) were applied. ${ }^{27}$ The results (Table 5) show that the calculated $t$ - and $F$-values did not exceed the theoretical values.

\section{Conclusion}

The two proposed methods have the potential for applications in quality control laboratories as they permit simple (as there is no need for solvent extraction), rapid, precise and accurate simultaneous determination of MB-SU mixtures in their pharmaceutical formulations. While the ${ }^{1} \mathrm{DD}$ method has greater sensitivity and accuracy, the easier treatment of the data by using CLS method makes it preferable to the ${ }^{1} \mathrm{DD}$. This is also true because CLS uses only zero order spectra in the procedures and has no need for any other mode, such as derivative mode in the instruments; but who need a software for the mathematical calculations.

\section{References}

1. K. Parfitt (ed.), "Martindale", The Extra Pharmacopoeia, 32th ed., 1999, Pharmaceutical Press, London, 692, 1199.

2. J. A. De Schutter, F. De Croo, G. Van der Weken, W. Van den Bossche, and P. De Moerloose, Chromatographia, 1985, 20, 185 .

3. O. Al-Deeb, B. M. Al-Hadiya, and N. H. Foda, Chromatographia, 1997, 44, 427.

4. M. C. Huang, H. O. Ho, G. C. Yeh, W. T. Ke, L. C. Lin, T. M. B. Hsu, C. C. Kao, and M. T. Sheu, J. Chromatogr., B: Biomed. Sci. Appl., 2001, 763, 157.

5. J. A. De Schutter, G. Van der Weken, W. Van den Bossche, and P. De Moerloose, J. Chromatogr., 1985, 350, 135.

6. J. A. De Schutter, G. Van der Weken, W. Van den Bossche, and P. De Moerloose, Chromatographia, 1985, $20,739$.

7. F. M. Abdel Gawad, Egypt. J. Anal. Chem., 1994, 3, 129.

8. E. M. Hassan, A. A. Gazy, and M. M. Bedair, Drug. Dev. Ind. Pharm., 1995, 21, 633 .

9. M. N. Reddy, K. V. S. Rao, D. G. Sankar, and K. Sridhar, Indian Drugs, 1996, 33, 604.

10. K. Sreedhar, C. S. P. Sastry, M. N. Reddy, and D. G. 
Sankar, Mikrochim. Acta, 1997, 126, 131

11. M. M. Bedair, M. A. Korany, M. A. Ebdel Hay, and A. A. Gazy, Analyst, 1990, 115, 449.

12. G. Alfredsson, G. Sedvall, and F. A. Wiesel, J. Chromatogr. Biomed. Appl., 1979, 164, 187.

13. F. Bressolle and J. Bres, J. Chromatogr. Biomed. Appl., $\mathbf{1 9 8 5}, 341,391$

14. H. Tokunaga, K. Kudo, N. Jitsufuchi, Y. Ohtsuka, and T. Imamura, J. Chromatogr. Biomed. Appl., 1997, 691, 203.

15. X. Yu, Z. Luo, J. S. Tang, and P. Yu, Sepu, 1997, 15, 546.

16. W. Han, L. Jiang, L. Gao, G. Zhou, and W. Jia, Zhongguo Yaoxue Zazhi, 1989, 24, 605, 639.

17. K. Dross, C. Sonntag, and R. Mannhold, J. Chromatogr., 1993, 639, 287.

18. M. Buna, J. J. Aaron, P. Prognon, and G. Mahuzier,
Analyst, 1996, 121, 1551.

19. Z. Liu and J. Zhang, Yaowu Fenxi Zazhi, 1993, 13, 279.

20. T. Zheng, S. F. Li, and B. Z. Xu, Yaowu Fenxi Zazhi, 1999, 19, 10.

21. F. A. Aly, N. A. Alarfaj, and A. A. Alwarthan, Talanta, 2001, 54, 715 .

22. X. Xu and J. T. Stewart, J. Pharm. Biomed. Anal., 2000, 23,735 .

23. Y. H. Zeng and H. Y. Ma, Fenxi Huaxue, 1997, 25, 56.

24. O. A. Farghaly, J. Pharm. Biomed. Anal., 2000, 23, 783.

25. A. F. M. El-Walily, A. El Gindy, and M. F. Bedair, $J$. Pharm. Biomed. Anal., 1999, 21, 535.

26. J. N. Miller, Analyst, 1991, 116, 3.

27. J. C. Miller and J. N. Miller, "Statistics for Analytical Chemistry", 3rd ed., 1993, Ellis Horwood, Chichester, 53. 